\title{
Significance of Polymorphism and Expression of miR-146a and NFkB1 Genetic Variants in Patients with Rheumatoid Arthritis
}

\author{
Katarzyna Bogunia-Kubik ${ }^{1,2}$ - Barbara Wysoczańska ${ }^{1}$ Dagmara Piątek ${ }^{1}$ • \\ Milena Iwaszko $^{1} \cdot$ Marzena Ciechomska $^{1,4} \cdot$ Jerzy Świerkot $^{3}$
}

Received: 21 July 2016/ Accepted: 18 October 2016/Published online: 12 January 2017

(c) The Author(s) 2016. This article is published with open access at Springerlink.com

\begin{abstract}
MicroRNA-146a (miR-146a) has been shown to play an important role in the regulation of inflammatory innate immune responses, and found to be differentially expressed in rheumatoid arthritis (RA). Through NF- $\mathrm{KB}$ pathway, this molecule is able to stimulate the release of proinflammatory cytokines such as TNF- $\alpha$, IL- $1 \beta$, and IL-17. It has been also suggested that single-nucleotide polymorphisms (SNPs) in miRNA sequences may alter miRNA expression and that miR-146a rs2910164 SNP may contribute to RA development. These observations prompted us to analyze the potential associations between the miR-146a$3 p$ (rs2910164, G > C) and NFkB1 (rs28362491, ins/del ATTG) polymorphisms and miR-146a-5p expression in patients' sera in relation to clinical outcome of the treatment as well as predisposition to RA. Genotyping was performed in 111 patients and 130 healthy individuals while 16 controls and 13 RA patients (before and after three months of therapy with TNF- $\alpha$ inhibitors (TNFi)) were studied for the circulating miR-146a-5p serum expression level. Patients carrying the NFkB1 ins/ins genotype were characterized by
\end{abstract}

Jerzy Świerkot

jurekswierkot0@poczta.onet.pl

1 Laboratory of Clinical Immunogenetics and Pharmacogenetics, Hirszfeld Institute of Immunology and Experimental Therapy, Polish Academy of Sciences, Wroclaw, Poland

2 Department of Internal, Occupational Diseases, Hypertension and Clinical Oncology, Wroclaw Medical University, Wroclaw, Poland

3 Department of Rheumatology and Internal Medicine, Wroclaw Medical University, Borowska 213, 50-556 Wroclaw, Poland

4 National Institute of Geriatrics Rheumatology and Rehabilitation, Warsaw, Poland worse response to TNFi treatment $(p=0.023)$. In patients, before TNFi therapy, expression levels of miR-146a-5p were less $(0.422 \pm 0.171)$ as compared to those detected after three months of treatment $(1.809 \pm 0.658, p=0.033)$ and observed for healthy controls $(5.302 \pm 2.112, p=0.048)$. Moreover, patients with higher circulating miR-146a-5p levels after three months of TNFi administration were more frequently carrying the $\operatorname{rs} 2910164-C$ allele $(p=0.032)$. These results support the hypothesis that miR-146a might be involved in pathogenesis of RA and imply that miR-146a-3p polymorphism may be associated with miR-146a-5p levels in serum after anti-TNF- $\alpha$ treatment.

Keywords Rheumatoid arthritis . miRNA-146a-3p polymorphism . miRNA-146a-5p serum level $\cdot N F k B 1$ polymorphism . Disease susceptibility $\cdot$ Response to treatment

\section{Introduction}

Rheumatoid arthritis (RA) is a systemic, inflammatory autoimmune disease primarily characterized by chronic synovitis and progressive joint destruction. The exact cause of RA remains unknown, however, it has been shown that both genetic and environmental factors play a role in the disease development (McInnes and Schett 2011). Anti-tumor necrosis factor (anti-TNF) biologic agents represent a novel approach in RA management that significantly improved the prognosis of RA patients. Although, substantial proportion of patients do not respond to the therapy with TNF inhibitors. The reasons of anti-TNF therapy failure have not been established to date. The search of biomarkers of anti-TNF agents' efficacy is of importance to optimize patient benefit and reduce cost of treatment. 
MicroRNAs (miRNAs, miRs) and nuclear factor kappalight-chain-enhancer of activated B cells $(\mathrm{NF}-\mathrm{\kappa B})$ are wellknown immune response and inflammation regulators.

MiRNAs are a family of single-stranded, non-coding endogenous regulatory molecules, cleaved from double stranded precursors, typically composed of 21-23 nucleotides. They are involved in the regulation of gene expression mainly at posttranscriptional level (Bartel 2009). It is estimated that the genes encoding the miRNA constitute $1-5 \%$ of the genes in humans and animals. A total of 2588 mature miRNAs were identified in humans (Eulalio and Mano 2015). More than 30\% of protein encoding genes in human cells are regulated by miRNA (Krol et al. 2010). A single miRNA molecule can simultaneously control the expression of hundreds of target genes.

MiRNAs are known to be the target for NF- $\mathrm{KB}$ transcriptional control and at the same time are involved in the modulation of NF- $\mathrm{\kappa B}$ signaling (Boldin and Baltimore 2012; Ghosh and Hayden 2008).

$\mathrm{NF}-\kappa \mathrm{B}$ regulates numerous pro-inflammatory cytokines, chemokines, and adhesion molecules involved in the activation and recruitment of inflammatory modulating cells (Ghosh and Hayden 2008). Patients with RA present constitutively high serum levels of pro-inflammatory cytokines, including TNF- $\alpha$, IL-1 $\beta$, IL- 6 or IL-17, which are known to be NF- $\mathrm{KB}$ target genes, suggesting activation of this signaling pathway in the course of disease.

Our former studies showed that genetic variability within genes coding for pro-inflammatory cytokines (Bogunia-Kubik et al. 2015; Świerkot et al. 2015) may play a role in RA development and response to treatment with TNF- $\alpha$ inhibitors (TNFi). It has been also documented that acting through NF- $\kappa B$ pathway, some miRNAs such as miR-146a and miR-155 may stimulate the release of proinflammatory cytokines. As the inflammatory mediators, these cytokines can induce lymphocytes, resident synovial cells, and other inflammatory cells to produce miRNAs that are related to disease activity of rheumatic disorders as shown for RA patients (Chen et al. 2015).

The miR-146 acts as a negative regulator of the TLR/ $\mathrm{NF}-\kappa \mathrm{B}$ signaling pathway. It was reported that the NF- $\mathrm{KB}$ activation may induce expression of the miR-146. On the other hand, miR-146 affects the expression of TNF receptor-associated factor 6 (TRAF6) and IL-1 receptorassociated kinase 1 (IRAK1), that constitute key adapter molecules involved in the Toll-like receptor (TLR)/NF- $\mathrm{BB}$ pathway. MiR-146-dependent downregulation of the TRAF6 and IRAK1 may result in inhibition of the TLR/ NF- $\kappa B$ signaling axis (Taganov et al. 2006). The $\mathrm{G}>\mathrm{C}$ substitution (rs2910164) at position +60 relative to the first nucleotide of the precursor mir-146a is a potentially functional single-nucleotide polymorphism (SNP) within the pre-mir-146a (5q33) gene that also occurs in the $3 p$ strand in mature miRNA. This SNP affects the amount of pre- and mature miRNA-146 through disruption of miRNA-146 processing (Jazdzewski et al. 2008). A direct functional effect of the rs2910164 polymorphism on the miRNA-146a capacity to inhibit its target genes (TRAF6 and IRAK1) has been also revealed (Jazdzewski et al. 2008). Taking into account that TRAF6 and IRAK1 have been implicated in RA pathogenesis, this polymorphism may contribute to RA development (Chatzikyriakidou et al. 2010).

There is a common insertion/deletion (-94 ins/del ATTG) polymorphism located within the $N F k B 1$ promoter (rs28362491) exerting functional effects on the transcription of the gene (Karban et al. 2004). This gene is located on chromosome $4 \mathrm{q} 24$ and encodes subunits p105 and p50 $\mathrm{kD}$ of NF- $\mathrm{kB}$. The p50 homodimer represses transcription of pro-inflammatory cytokines and stimulates transcription of anti-inflammatory cytokines (Cartwright et al. 2016).

The aim of the present study was to analyze potential associations between $N F k B 1$ (rs28362491, ins/del ATTG) and $m i R-146 a-3 p$ (rs2910164, G > C) polymorphisms and miR-146a-5p expression in patients' sera in relation to clinical outcome of the treatment as well as predisposition to RA.

\section{Materials and Methods}

\section{Genotyping Studies}

DNA was isolated from peripheral blood of 111 RA patients hospitalized at the Rheumatology Clinic of the Medical University in Wroclaw and 130 healthy individuals that served as a control group for disease association studies. Patients and controls were genotyped for the miR-146a-3p (rs2910164, G > C) alleles using a polymerase chain reaction (PCR) amplification employing the LightSNiP assay (TIB MOLBIOL, Berlin, Germany). Capillary electrophoresis or PCR followed by restriction fragment length polymorphism (PCR-RFLP with PflMl digestion) were employed to study the NFkB1 (rs28362491, ins/del ATTG) alleles, as previously described by Zhou et al. (2009) and Koc et al. (2014), respectively. Separation of PCR products was performed in a $50 \mathrm{~cm} 8$ capillary array containing POP-7 polymer on 3500 Genetic Analyzer (Applied Biosystem, USA) and analyzed by GeneMapper Software v 4.2 (Applied Biosystem, USA). Both techniques gave the same results with $100 \%$ concordance in duplicate samples. 
The study was approved by the Wroclaw Medical University Ethics Committee and written informed consent was obtained from all participants.

\section{Analysis of Circulating miR-146a-5p Expression}

For analysis of the miR-146a-5p expression, RNA was isolated from sera of 13 patients (before and three months after anti-TNF- $\alpha$ treatment) and 16 healthy controls with the use of Nucleospin ${ }^{\circledR}$ miRNA Plasma (MACHEREYNAGEL GmbH\&Co.KG). Reverse transcription was conducted using TaqMan ${ }^{\circledR}$ MicroRNA Reverse Trascription Kit Cat. \# 4,366,596 (Applied Biosystems, Life Technologies), in accordance with the manufacture's protocol. The reaction was carried out in a SimpliAmpTM Thermal Cycler (Applied Biosystems, Life Technologies) at $16{ }^{\circ} \mathrm{C}$ for $30 \mathrm{~min}, 42{ }^{\circ} \mathrm{C}$ for $30 \mathrm{~min}$, and $85^{\circ} \mathrm{C}$ for $5 \mathrm{~min}$. The product of reverse transcription was stored at $-20{ }^{\circ} \mathrm{C}$ until further use.

Expression of miR-146a-5p was analyzed by Real Time PCR. The reaction was performed on a ViiaTM 7 Real Time PCR System (Applied Biosystems) using the TaqMan microRNA Assay quantitate miRNAs: hsa-miR-146a-5p Cat. \# 4,427,975 primers for human miR-146a-5p and U6 together with TaqMan Universal PCR Master Mix II, no UNG Cat. \# 4,440,040 (Applied Biosystems). MiR-146a-5p expression was normalized to U6, which was endogenous small nuclear RNA control (TaqMan MicroRNA Assays, Applied Biosystems). All reactions were carried out in duplicates. The results were analyzed using the $(\Delta \Delta \mathrm{Ct})$ calculations. The data are presented as mean \pm SEM.

\section{Statistical Analysis}

All genotypes were tested for deviations from HardyWeinberg equilibrium (HWE) using the $\chi^{2}$ test. Fisher's exact test was used to compare the allele and genotype frequencies between patients and controls.

The differences in miR-146a-5p serum expression levels between the groups were tested by non-parametric twotailed $T$ test or Wilcoxon matched-pairs rank test. A $p$ value of less than 0.05 was considered statistically significant.

\section{Results}

\section{Distribution of the miR-146a and NFkB1 Genotypes in Patients and Controls}

We found no evidence that genotype frequencies of the two polymorphisms examined were different from those expected from HWE both in controls and cases. There was no linkage disequilibrium between the studied polymorphisms. Genotype distributions of both SNPs were similar between patients and controls (Table 1). Thus, neither the rs2910164 miR-146a-3p nor the rs28362491 NFkB1 polymorphism was found to be associated with predisposition to RA. Furthermore, no significant relationship was detected for any of parameters such as: anti-cyclic citrullinated peptide antibodies, rheumatoid factor, C-reactive protein and disease activity score (DAS28) (individual data not shown).

\section{Response to TNFi Treatment}

Clinical response was evaluated according to the European League Against Rheumatism criteria at the third month after initiation of the TNFi therapy (Fransen and van Riel 2005).

The NFkB1 ins/del polymorphism was found to be associated with response to the biological treatment. Patients homozygous for the ins allele appeared to be worse responders as compared to the del allele carriers. The ins/ins genotype was detected in 11 out of $18(61 \%)$ of patients with unsuccessful outcome of the treatment and only in 16 out of $56(18 \%)$ of those for whom the therapy was successful ( $p=0.023$; Fig. 1).

Moreover, some significant differences were observed with respect to the expression levels of circulating miR146a-5p. Patients after three months of TNFi administration had higher miR-146a-5p levels in serum than those before the treatment (4.3-fold increase; $1.809 \pm 0.658$ vs $0.422 \pm 0.171, p=0.033$; Fig. 2a) and they were more frequently carrying the $m i R-146 a C$ allele (the gray dots on the graph; Fig. 2b). Four out of five patients (80\%) carrying the $C$ variant presented with increased serum levels after

Table 1 Distribution of rs2910164 miR-146a-3p and rs28362491 NFkB1 genotypes in RA patients and controls

\begin{tabular}{llllc}
\hline Gene & Polymorphism & Genotype & RA patients & Controls \\
\hline miR-146a-3p & rs2910164 & GG & $72(65 \%)$ & $88(68 \%)$ \\
& & GC & $32(29 \%)$ & $36(28 \%)$ \\
NFkB1 & GC & ins/ins & $7(6 \%)$ & $6(4 \%)$ \\
& & ins $/$ del & $36(33 \%)$ & $69(55 \%)$ \\
& & del/del & $55(50 \%)$ & $14(11 \%)$ \\
\hline
\end{tabular}




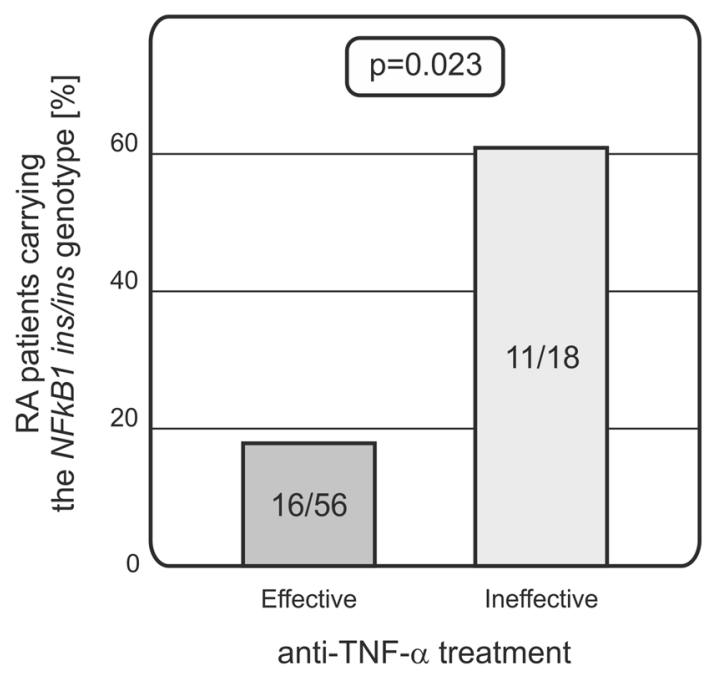

Fig. 1 Relationship between the $N F k B 1$ polymorphism and response to treatment in RA patients

TNFi treatment as compared to only one out of eight $(12.5 \%)$ of the $G G$ homozygous patients $(p=0.032$; Fig. 2b). Expression was higher in controls as compared to the patients, especially those before TNFi treatment (2.9fold; $\quad 5.302 \pm 2.112$ vs $1.809 \pm 0.658, \quad p=0.048$; Fig. 2a). The NFkB1 ins/del polymorphism was not found to affect the serum expression level of circulating miR146a.

\section{Discussion}

The results of the present study suggest that miR-146a might play an important role in the pathogenesis of RA. Serum expression levels of miR-146a-5p were significantly reduced in patients as compared to healthy individuals. Moreover, increase of miR-146a-5p expression levels was observed in patients after three months of anti-TNF- $\alpha$ therapy. This observation indicates that administration of anti-TNF- $\alpha$ drugs gradually increases the miR-146-5p level in patients' sera, potentially up to the level observed for healthy controls. Our data also imply that miR-146a-3p rs2910164 polymorphism may be associated with miR146a-5p levels in serum after TNFi treatment, with higher levels observed for the $C$ allele carriers. However, this genetic variant did not influence the predisposition to RA or efficacy of anti-TNF- $\alpha$ therapy.

In line with the results of our present study, the reduced miR-146a serum expression levels have been previously reported by Filková et al. (2014) in patients with early RA as compared to healthy controls. Also, significantly reduced serum levels of miRNA-146a were observed in patients with established RA (Wang et al. 2012). Moreover, changes of miR-146a levels in sera of RA patients before and after anti-TNF treatment have been investigated in the study by Castro-Villegas et al. (2015). Consistent with our results, serum expression levels of the miR-146a were significantly upregulated in patients following anti-TNF therapy (Castro-Villegas et al. 2015). On the other hand, elevated expression of the miR-146a was observed in synovial tissues, synovial fluid monocytes, peripheral blood-derived mononuclear cells, and serum from RA patients (Murata et al. 2010; Pauley et al. 2008).

The previous studies documented that the miR-146a SNP may be associated with predisposition to metabolic syndrome development (Mehanna et al. 2015) or carcinogenesis (Jazdzewski et al. 2008; Wojcicka et al. 2014). As for the miR-146a SNP, some associations with pathogenesis of rheumatic diseases have been described especially for patients with ankylosing spondylitis in a Han Chinese population (Xu et al. 2015). However, this SNP has not been reported to be associated with RA in either Asian or Caucasian populations (Chatzikyriakidou et al. 2010; ElShal et al. 2013; Zhou et al. 2015; the present study). Although, in a study of Zhou et al. (2015), a significant association of the $G G$ genotype with RA in females was observed, while the $C C$ homozygosity seemed to be correlated with the DAS28 score.

With respect to the NFkB1 (rs28362491, ins/del ATTG) polymorphism, the previous studies documented that it may affect the susceptibility to various diseases, e.g., cancer (Bu et al. 2007; Cartwright et al. 2016), autoimmune disorders including ulcerative colitis (Karban et al.
Fig. 2 Serum expression levels of miR-146a-5p in RA patients (before and after 3 months of TNFi treatment) and controls (a) and changes in miR-146-5p expression profile in RA patients with respect to the presence of the $C$ polymorphic variant (marked in gray) of the $m i R-146 a-3 p$ (rs2910164) SNP (b)
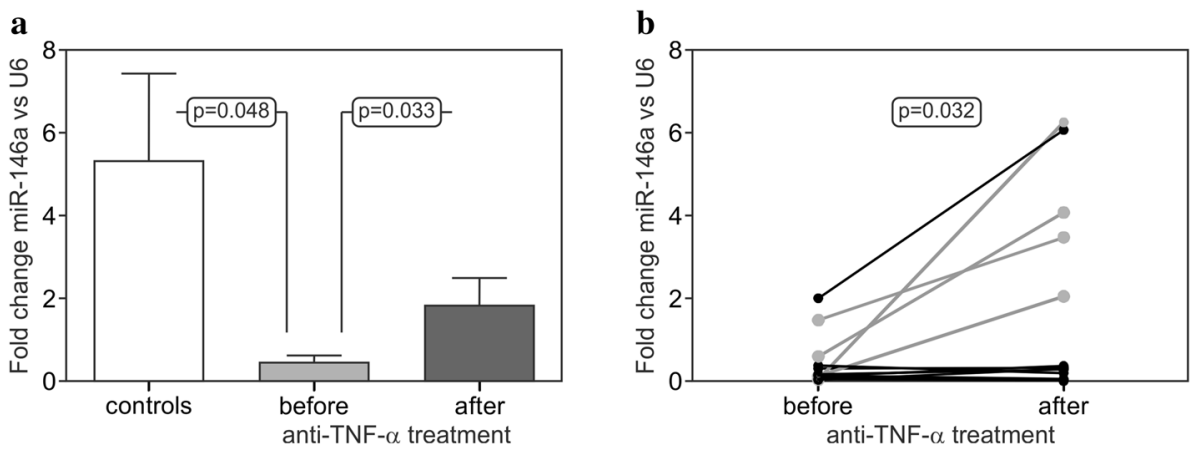
2004) or cardiovascular disease in patients with RA (López-Mejías et al. 2012).

Our genotyping results seem to be in agreement with those previously published. The frequency of the del allele was formerly reported to vary $32-54 \%$ between various ethnic populations, compared with 42 and $39 \%$ for patients and controls of the present study (Amador et al. 2016; Koc et al. 2014). However, we did not find any association with predisposition to RA. Nevertheless, we did observe some relationships with the treatment outcome.

The ins/ins homozygosity was found to be associated with worse response to therapy with TNFi. Interestingly, a comparison of the differences in miR-146a serum levels before and three months after TNFi treatment showed that patients lacking this ins/ins homozygous genotype had over three times higher mean difference between serum levels at these two time points ( 1.748 vs $0.558 \mathrm{pg} / \mathrm{mL}, p=0.093$ ) as compared to those carrying ins/ins homozygosity that were characterized by similar circulating miR-146a levels.

Results from the in vitro functional study (Karban et al. 2004) suggest that the presence of the deletion may be associated with diminished expression of the gene, leading to reduced $\mathrm{p} 50 / \mathrm{p} 105 \mathrm{NF}-\kappa \mathrm{B}$ protein production. Since p50 has been shown to repress the production of pro-inflammatory cytokines, including TNF- $\alpha$ (Pereira and Oakley 2008), beneficial role of ins genotype in context of antiTNF treatment outcome may be expected.

Indeed, it was observed that the presence of the del allele enhances production of pro-inflammatory cytokines such as, for example, IL-6 (44.23 vs $14.80 \mathrm{pg} / \mathrm{mL}$, for del/ del vs ins/ins genotypes; Koc et al. 2014) or TNF- $\alpha$ (91.32 vs 66.10 vs $40.73 \mathrm{pg} / \mathrm{mL}$, for $\mathrm{del} / \mathrm{del}$, del/ins, ins/ins genotype carriers, respectively; our unpublished results).

However, in the present study, the ins/ins genotype correlated with worse response to anti-TNF therapy. Nonetheless, it should be noted that in vitro studies involving a restricted set of biological factors may not reflect interactions occurring in vivo in a disease environment. Furthermore, the ins variant has been previously documented as a risk factor of other autoimmune-related diseases such as psoriasis ( $\mathrm{Li}$ et al. 2008) or Behcet's disease (Yenmis et al. 2015). Moreover, recently performed meta-analysis concerning a role of the polymorphism in autoimmune disorders revealed the favorable effect of the del allele (Zou et al. 2011).

In summary, these preliminary results support the hypothesis that miR-146a might be involved in pathogenesis of RA as differences in serum levels were observed during therapy with TNF- $\alpha$ inhibitors. The results of the present study also suggest that the miR-146a polymorphism may be associated with miRNA levels in serum after anti-TNF- $\alpha$ treatment while the $N F k B 1$ polymorphism may affect the efficacy of the therapy. Obviously, these observations should be confirmed in a more extensive study. More research is needed to delineate the mechanism of NF- $\kappa \mathrm{B}$ and miR-146a action underlying inflammatory response in $\mathrm{RA}$.

Acknowledgements This project was supported in part by the Wroclaw Centre of Biotechnology, The Leading National Research Centre (KNOW) program for years 2014-2018. The authors thank the Regional Centre of Transfusion Medicine and Blood Bank in Wroclaw for providing control blood samples.

Open Access This article is distributed under the terms of the Creative Commons Attribution 4.0 International License (http:// creativecommons.org/licenses/by/4.0/), which permits unrestricted use, distribution, and reproduction in any medium, provided you give appropriate credit to the original author(s) and the source, provide a link to the Creative Commons license, and indicate if changes were made.

\section{References}

Amador MA, Cavalcante GC, Santos NP et al (2016) Distribution of allelic and genotypic frequencies of IL1A, IL4, NFKB1 and PAR1 variants in Native American, African, European and Brazilian populations. BMC Res Notes 9:101

Bartel DP (2009) MicroRNAs: target recognition and regulatory functions. Cell 136:215-233

Bogunia-Kubik K, Świerkot J, Malak A et al (2015) IL-17A, IL-17F and IL-23R gene polymorphisms in Polish patients with rheumatoid arthritis. Arch Immunol Ther Exp 63:215-221

Boldin MP, Baltimore D (2012) MicroRNAs, new effectors and regulators of NF- $\kappa B$. Immunol Rev 246:205-220

$\mathrm{Bu} \mathrm{H}$, Rosdahl I, Sun XF et al (2007) Importance of polymorphisms in $\mathrm{NF}-\kappa \mathrm{B} 1$ and $\mathrm{NF} \kappa \mathrm{BI} \alpha$ genes for melanoma risk, clinicopathological features and tumor progression in Swedish melanoma patients. J Cancer Res Clin Oncol 133:859-866

Cartwright T, Perkins ND, Wilson CL (2016) NFKB1: a suppressor of inflammation, ageing and cancer. FEBS J 283:1812-1822

Castro-Villegas C, Pérez-Sánchez C, Escudero A et al (2015) Circulating miRNAs as potential biomarkers of therapy effectiveness in rheumatoid arthritis patients treated with anti-TNF $\alpha$. Arthritis Res Ther 17:49

Chatzikyriakidou A, Voulgari PV, Georgiou I et al (2010) A polymorphism in the $3^{\prime}$-UTR of interleukin- 1 receptor-associated kinase (IRAK1), a target gene of miR-146a, is associated with rheumatoid arthritis susceptibility. Joint Bone Spine $77: 411-413$

Chen XM, Huang QC, Yang SL et al (2015) Role of Micro RNAs in the pathogenesis of rheumatoid arthritis: novel perspectives based on review of the literature. Medicine 94:e1326

El-Shal AS, Aly NM, Galil SM et al (2013) Association of microRNAs genes polymorphisms with rheumatoid arthritis in Egyptian female patients. Joint Bone Spine 80:626-631

Eulalio A, Mano M (2015) MicroRNA screening and the quest for biologically relevant targets. J Biomol Screen 20:1003-1017

Filková M, Aradi B, Šenolt L et al (2014) Association of circulating miR-223 and miR-16 with disease activity in patients with early rheumatoid arthritis. Ann Rheum Dis 73:1898-1904

Fransen J, van Riel PL (2005) The disease activity score and the EULAR response criteria. Clin Exp Rheumatol 23(5 suppl):S93S99

Ghosh S, Hayden MS (2008) New regulators of NF-kappaB in inflammation. Nat Rev Immunol 8:837-848 
Jazdzewski K, Murray EL, Franssila K et al (2008) Common SNP in pre-miR-146a decreases mature miR expression and predisposes to papillary thyroid carcinoma. Proc Natl Acad Sci USA 105:7269-7274

Karban AS, Okazaki T, Panhuysen CI et al (2004) Functional annotation of a novel NFKB1 promoter polymorphism that increases risk for ulcerative colitis. Hum Mol Genet 13:35-45

Koc A, Batar B, Celik O et al (2014) Polymorphism of the NFKB1 affects the serum inflammatory levels of IL-6 in Hashimoto thyroiditis in a Turkish population. Immunobiology 219:531-536

Krol J, Loedige I, Filipowicz W (2010) The widespread regulation of microRNA biogenesis, function and decay. Nat Rev Genet 11:597-610

Li H, Gao L, Shen Z et al (2008) Association study of NFKB1 and SUMO4 polymorphisms in Chinese patients with psoriasis vulgaris. Arch Dermatol Res 300:425-433

López-Mejías R, García-Bermúdez M, González-Juanatey C et al (2012) NFKB1-94ATTG ins/del polymorphism (rs28362491) is associated with cardiovascular disease in patients with rheumatoid arthritis. Atherosclerosis 224:426-429

McInnes IB, Schett G (2011) The pathogenesis of rheumatoid arthritis. N Engl J Med 365:2205-2219

Mehanna ET, Ghattas MH, Mesbah NM et al (2015) Association of microRNA-146a rs2910164 gene polymorphism with metabolic syndrome. Folia Biol 61:43-48

Murata K, Yoshitomi H, Tanida S et al (2010) Plasma and synovial fluid microRNAs as potential biomarkers of rheumatoid arthritis and osteoarthritis. Arthritis Res Ther 12:R86

Pauley KM, Satoh M, Chan AL et al (2008) Upregulated miR-146a expression in peripheral blood mononuclear cells from rheumatoid arthritis patients. Arthritis Res Ther 10:R101

Pereira SG, Oakley F (2008) Nuclear factor-kappaB1: regulation and function. Int J Biochem Cell Biol 40:1425-1430
Świerkot J, Bogunia-Kubik K, Nowak B et al (2015) Analysis of associations between polymorphisms within genes coding for tumour necrosis factor (TNF)-alpha and TNF receptors and responsiveness to TNF-alpha blockers in patients with rheumatoid arthritis. Joint Bone Spine 82:94-99

Taganov KD, Boldin MP, Chang KJ et al (2006) NF-kappaBdependent induction of microRNA miR-146, an inhibitor targeted to signaling proteins of innate immune responses. Proc Natl Acad Sci USA 103:12481-12486

Wang H, Peng W, Ouyang X et al (2012) Circulating microRNAs as candidate biomarkers in patients with systemic lupus erythematosus. Transl Res 160:198-206

Wojcicka A, de la Chapelle A, Jazdzewski K (2014) MicroRNArelated sequence variations in human cancers. Hum Genet 133:463-469

Xu HY, Wang ZY, Chen JF et al (2015) Association between ankylosing spondylitis and the miR-146a and miR-499 polymorphisms. PLoS One 10:e0122055

Yenmis G, Oner T, Cam C et al (2015) Association of NFKB1 and NFKBIA polymorphisms in relation to susceptibility of Behçet's disease. Scand J Immunol 81:81-86

Zhou B, Rao L, Peng Y et al (2009) Functional polymorphism of the NFKB1 gene promoter is related to the risk of dilated cardiomyopathy. BMC Med Genet 10:47

Zhou X, Zhu J, Zhang $\mathrm{H}$ et al (2015) Is the microRNA-146a (rs2910164) polymorphism associated with rheumatoid arthritis? Association of microRNA-146a (rs2910164) polymorphism and rheumatoid arthritis could depend on gender. Joint Bone Spine 82:166-171

Zou YF, Wang F, Feng XL et al (2011) Association of NFKB1 -94ins/ del ATTG promoter polymorphism with susceptibility to autoimmune and inflammatory diseases: a meta-analysis. Tissue Antigens 77:9-17 